\title{
Developing an Innovative and Creative Hands-on Lean Six Sigma Manufacturing Experiments for Engineering Education
}

\author{
Isam Elbadawi \\ Industrial Engineering \\ University of Hail \\ Hail, Saudi Arabia \\ i.elbadawi@uoh.edu.sa, isam149@gmail.com
}

\author{
Mohamed Aichouni \\ Industrial Engineering \\ University of Hail \\ Hail, Saudi Arabia \\ m_aichouni@yahoo.co.uk
}

\author{
Noor Aite Messaoudene \\ Mechanical Engineering \\ University of Hail \\ Hail, Saudi Arabia \\ n.messaoudene@uoh.edu.sa
}

\begin{abstract}
The goal of this study was to develop an innovative and creative hands-on project based on Lean Six Sigma experiments for engineering education at the College of Engineering at the University of Hail. The exercises were designed using junction box assembly to meet the following learning outcomes: 1-to provide students with solid experience on waste elimination and variation reduction and 2-to engage students in exercises related to assembly line mass production and motion study. To achieve these objectives, students were introduced to the principles of Lean manufacturing and Six Sigma through various pedagogical activities such as classroom instruction, laboratory experiments, hands-on exercises, and interactive group work. In addition, Minitab 17 statistical package and Quality Companion 3 software were used to facilitate The Lean Six Sigma exercises. The software application and hands-on manufacturing assembly were found to be extremely valuable in giving students the chance to identify which variables to control in order to minimize variation and eliminate waste. This research was funded by a grant from the Deanship of Academic Research at University of Hail for project number E26-IC, and under the umbrella of Ministry of Education within the framework of the National Initiative on Creativity and Innovation in Saudi Universities at University of Hail.
\end{abstract}

Keywords-innovation; creativity; engineering; education; Lean manufacturing; Six Sigma; hands-on

\section{INTRODUCTION}

The power that Six Sigma holds to accelerate innovation is through its inherent focus on continuous improvement. By a disciplined approach to innovative Six Sigma methodologies, efforts can be focused on identifying the hands-on activities that require a small time investment but deliver high learning effect. Projects can then be prioritized for maximum employee workload reduction. Utilizing Six Sigma methodologies, organizations have the potential of reducing employee frustration while simultaneously increasing the employee energy available to focus on innovation.

\section{A. Hands-on Approach}

It is often argued that engineering education must integrate engineering theory and practice in order to become more relevant to the needs of both students and market place. Such integration is particularly important not only because the world has changed tremendously and new challenges have surfaced over the last decade, but also because a considerable number of the students who join engineering schools have probably never had their hands on any practical engineering project. At the present, this integration has become an essential practice in most engineering schools worldwide. However, the number and complexity of the project-based courses significantly vary among institutions with some having a project-based component to almost every engineering course [1] and others that have only a few of such projects. This issue becomes even more challenging when considering how to integrate theoretical concepts with the necessary training required for the production and manufacturing in the real world $\lceil 2\rceil$. When hands-on projects are appropriately combined with virtual manufacturing software in the engineering education system, they do not only add value to the education and training of students, but become an essential component of the educational process [3].

\section{B. Lean Manufacturing}

In [6], a work based on a three-year MIT study in the automotive industry was described. The study showed that Toyota outperformed the major US car manufacturers by a factor of 2:1 on quality, cost and time to market. They coined the term "Lean" to describe the way the Toyota Production System (TPS) sought to continually identify and eliminate waste. They described "Lean" as a fundamentally different system "of thinking about how humans work together to add value"[7]. The term "Lean" focuses on solving simple and minor problems and on the removal of waste. Indeed, an important assumption underlying the Lean methodology is that waste is the main limitation on profitability and that numerous and rapid improvements are more beneficial than analytical study.

\section{Lean Six Sigma}

Lean manufacturing and Six Sigma are often viewed as today's two most important initiatives. Therefore, the combination of these two techniques is believed to greatly improve the manufacturing process and to eliminate waste in time and money through simultaneously reducing variation and 
improving manufacturing bottom line [4]. Six Sigma is a metric refers to 3.4 defects per million opportunities (DPMO), where Sigma is a statistical term representing the variation around the process mean. How do Lean and Six Sigma complement each other? This was an important question raised. It has been argued that Lean cannot bring a process under statistical control, and Six Sigma alone cannot dramatically accelerate the speed of the manufacturing process or reduce invested capital [5]. Therefore, a combination of the two resulted in Lean Six Sigma defined as "a methodology that maximizes shareholder value by achieving the fastest rate of improvement in customer satisfaction, cost, quality, process speed and invested capital" [5]. Table I below summarizes some of the Six Sigma tools and techniques that are applicable to the exercise projects described in this study.

TABLE I. DMAIC METHODOLOGY

\begin{tabular}{|c|c|c|c|c|}
\hline Objective: & Objective: & Objective: & Objective: & Objective: \\
\hline $\begin{array}{l}\text { DEFINE the } \\
\text { problem (i.e } \\
\text { opportunity) }\end{array}$ & $\begin{array}{l}\text { MEASURE } \\
\text { current } \\
\text { performance }\end{array}$ & $\begin{array}{l}\text { ANALYZE } \\
\text { the root } \\
\text { causes of } \\
\text { problems }\end{array}$ & $\begin{array}{l}\text { IMPROVE the } \\
\text { process to } \\
\text { eliminate root } \\
\text { causes }\end{array}$ & $\begin{array}{l}\text { CONTROL } \\
\text { the process } \\
\text { to sustain the } \\
\text { gains. }\end{array}$ \\
\hline $\begin{array}{l}\frac{\text { Key Define }}{\text { Tools: }} \\
\text { House of } \\
\text { Quality } \\
\text { Project } \\
\text { Charter } \\
\text { As-Is } \\
\text { Process } \\
\text { SIPOC }\end{array}$ & $\begin{array}{l}\frac{\text { Key }}{\text { Measure }} \\
\underline{\text { Tools: }} \\
\text { (CTQs) } \\
\text { Capability } \\
\text { Analysis } \\
\text { (FMEA) }\end{array}$ & $\begin{array}{l}\frac{\text { Key }}{\text { Analyze }} \\
\underline{\text { Tools: }} \\
\text { Seven Tools, } \\
\text { Hypothesis } \\
\text { Tests } \\
\text { Regression } \\
\text { Analysis }\end{array}$ & $\begin{array}{c}\text { Key Improve } \\
\text { Tools: } \\
\text { Solution } \\
\text { Selection } \\
\text { Matrix } \\
\text { To-Be Process } \\
\text { Map(s) }\end{array}$ & $\begin{array}{c}\frac{\text { Key Control }}{\text { Tools: }} \\
\text { Control Charts } \\
\text { Contingency } \\
\text { and/or Action } \\
\text { Plan(s) }\end{array}$ \\
\hline
\end{tabular}

\section{Statement of Problem}

The problem of this research project is to develop a feasible way to impart the Lean Six Sigma knowledge, principles, and tools to the real production and processing manufacturing through hands-on exercises.

\section{E. Research Objectives}

The researchers embarked on this study with the purpose of developing and testing a hands-on project based on Lean Six Sigma exercises. The target students were those majoring in Industrial and Mechanical Engineering at the University of Hail $(\mathrm{UoH})$ and enrolled in the Quality and Manufacturing courses during the first semester of the academic year 2015-2016. The general objective of this study is twofold:

1. To provide students with a solid experience on waste elimination and variation reduction

1. To engage students in exercises related to the assembly line mass production and motion study

For the most part, the designed exercises focused on providing students with a solid theoretical introduction to the fundamentals of Lean Six Sigma and to the analytical skills necessary for manufacturing process improvement. Conversely, the hands-on project was designed to provide students with the know-how procedures for translating hands-on scale exercises processes to the factory floor.
The educational objectives of the "Lean Six Sigma handson exercises" are to:

1. introduce students to manufacturing process improvement methodologies, including hands-on experience with statistical and quality software

2. familiarize students with analytical methods to characterize, assess, and qualify these manufacturing process improvement methodologies

3. introduce Six Sigma quality methods as applied to manufacturing process improvement methodologies

4. familiarize students with the principles of Lean Manufacturing in an exercise setting that simulates a small manufacturing enterprise performing lowvolume and mix production

\section{RESEARCH METHOD}

The study adapted a design for manufacturing washers, bolts, and nuts (WBN) assembly junction box described in [3] as a hands-on tool for students of industrial engineering at the University of Hail. The junction box assembly was designed with a thorough understanding of the downstream manufacturing process and the assembly procedures were modified by the assembly team based on the feedback provided by the manufacturing designer. The variation of the WBN in junction box assembly enabled the teams to conduct several hands-on exercises in multiple concepts related to Lean Six Sigma such as:

1. manufacturing process flow, variation journal development, waste identification

2. visual control, $5 \mathrm{~S}$, waste elimination

3. pull production system

4. work standardization

5. DMAIC

The junction box assembly consists of the materials illustrated in Figures 1.

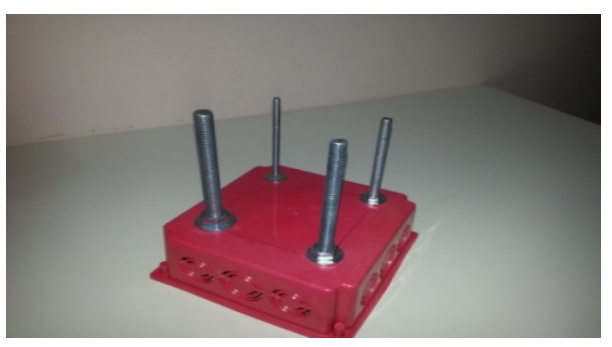

Fig. 1. Water proof plastic junction box

\section{A. Design for Assembly Manufacturing Procedures}

Each junction box assembly consists of one plastic junction box with one piece of each size of the bolts, nuts, and washers. The following steps were used to manufacture the assembly [3]: 
1. marking the drilling points for each bolt using the $12 \mathrm{~cm}$ $\times 12 \mathrm{~cm}$ marking square

2. drilling the corners of the marked square with the appropriate bits starting with $6 \mathrm{~mm}$ continuing the drilling process clock wise ascending to $12 \mathrm{~mm}$ hole size

3. basic Assembly: attaching each bolt to the appropriate hole as shown in figure

4. installing the appropriate washer to each bolt

5. tightening each nut to the appropriate bolt

6. repeating the above steps to manufacture 24 units

\section{B. Lean Six Sigma Models}

The variables $(\mathrm{Y})$ and $(\mathrm{X})$ are defined in each model based on the installed components in each exercise according to specific instructions and procedures. Each model represents a real mimic of actual manufacturing processing and production paradigm such as Push-Pull system, Lean Manufacturing, Visual Workplace, Inventory Control, Poke Yoke, 5S, etc. The authors designed the Lean Six Sigma models to achieve the following create:

1. a smooth flow of the assembly process model

2. a clear and clean visual control model

3. a pull system model

4. a standardization of the tasks for each model

Each model shows how the manufacturing assembly rate of washers, bolts, nuts was improved and stabilized along with the use of Lean Six Sigma tools. Also, it shows the variation among the completed junction box assembly as a critical to quality (CTQ) to measure the performance indicator from Lean Six Sigma principles.

One of the main goals of Lean and Six Sigma models was to measure the process capability index $(\mathrm{Cp})$. Cp can be calculated using the following equation [8]:

$$
\mathrm{Cp}=(\mathrm{USL}-\mathrm{LSL}) / 6 \sigma(1)
$$

If only USL and LSL are given, where: USL=upper specification given, $\mathrm{LSL}=$ lower specification given, $\sigma=$ standard deviation of the data.

In this research, $\mathrm{Cp}$ is constructed to express more desirable capability with in junction box assembly rate. The authors have developed a set of models using the junction box assembly, and each model was abstracted as shown in Figure 2.

\section{Xn Independent variables}

Design for assembly manufacturing process

Yn Dependent variables

Fig. 2. Six Sigma Abstract model Diagram

\section{Lean Six Sigma Exercise}

The Lean Six Sigma exercises format described here is sufficiently generic that it can be adapted for many different types of manufacturing systems. Most of the exercises, as originally developed, require one or two several-hour of handson sessions to complete, but the addition of Six Sigma tasks added several hours to each hands-on session. These exercises have well-documented procedures and protocols, including supplemental instructional detailing each step of the exercise. The students assembled different models aimed at generating quantitative data that provides instructive examples in applying Lean Six Sigma techniques to the manufacturing processes.

A Lean Six Sigma exercise starts with a problem statement followed by defining the primary metric, which aids to focus on the problem area and measures the input $(\mathrm{X})$ and output or resulting (Y). The primary metric for this exercise was the "the count of washers, bolts, nuts' in addition to the arrangement of each set. To illustrate the common cause and the special cause variation in a typical Lean Six Sigma process, the critical X's which are the input to the process are represented in Figure 3. The Lean process always starts with identifying the value which is represented with the completion of assembling the correct size of washers and nuts on each bolt starting from with the $6 \mathrm{~mm}$ to $12 \mathrm{~mm}$ clockwise assembly sequence. The Value Stream Mapping (VSM) is the second step to determine the potential Xs. As shown in Figure 3, it shall be noted that the output or resulting Y may also be variable, due to variations in the inputs. In this case, the prime $\mathrm{Y}$ is the completion rate of the Junction box model.

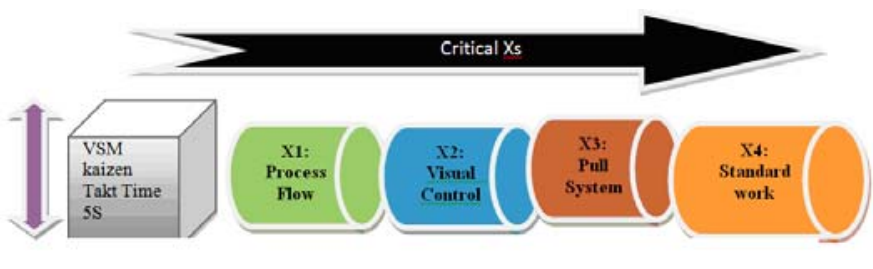

Fig. 3. Lean Six Sigma implementation model

\section{Define phase}

After being introduced to the exercise procedures, students were divided into teams and each team had a champion. The champion had to select an appropriate Black Belt and formulate tasks that must be undertaken during the define phase. These tasks include:

1. refining feasible exercise scope

2. setting-up exercise goals

3. estimating exercise challenges

Because the time period of each Lean Six Sigma exercise is limited to a single academic semester, each exercise must have a suitable scope if it is to be successfully completed on time. In this phase students learn how to define the problem (i.e the opportunity). This phase guides the team to specify the variables for the opportunity effectively and to justify the commitment of resources so as to achieve the exercise goals. 
Various tools are used during this phase to ensure that the scope of the exercise and the opportunity are adequately defined namely 5S, CTQ, project charter, and VSM. Data related to the opportunity formulation was based on first time students indulge in the Lean Six Sigma exercise.

\section{E. Formulating the opportunity}

The opportunity formulated by the team was as follows: The current assembly rate for the washers, nuts, and bolts for one junction box is 70 pieces in 700 seconds. The goal set was to increase the rate to 99 pieces in 700 seconds by the end of the exercise.

\section{F. Project charter}

Assembly starts as the conveyor begins to movement until the Junction box assembly reaches the packaging spot. The $6 \mathrm{~mm}$ nuts were identified as a critical bottleneck for efficient junction box production flow. The misplacement of any item translates into a reduction in effective assembly capability, process delays and unsatisfied customer.

\section{G. Voice of the Customer (VOC)}

A number of brainstorming sessions were held to discuss students and instructors' observations about the assembly process. The outcome of these sessions indicated that there were several opportunities for improving the structure and processes related to the quality of assembly coordination. Also VOC indicated that the assembly process took longer than necessary and therefore negatively impacting the assembly completion rate. However, there are many opportunities to minimize unnecessary changes by improving the interaction process among teams. Therefore, the researchers applied Lean Six Sigma approaches to the assembly process in order to exclusively focus on reducing the assembly time.

\section{H. Measure Phase}

At this stage, the collected data was evaluated and Sigma was calculated. The process baseline was established and each process in this phase had the purpose of mapping the assembly process and establishing methodology that describes the study in order to narrow the problem to its major factors. A tool such as the measurement system analysis (MSA) can be used in the measure phase to ensure accuracy. As Table II below show, students were able to measure standard time and count for each size of the washers, bolts, and nuts assembly in junction box.

TABLE II. STANDARD TIME AND COUNT

\begin{tabular}{|c|c|c|c|c|c|c|}
\hline & & $6 \mathrm{MM}$ & $8 \mathrm{MM}$ & $10 \mathrm{MM}$ & $12 \mathrm{MM}$ & Total \\
\hline All & Standard time $/ \mathrm{sec}$ & 270 & 180 & 150 & 100 & 700 \\
\hline & standard count & 32 & 28 & 22 & 18 & 100 \\
\hline washers & Standard time $/ \mathrm{sec}$ & 2 & 2 & 2 & 2 & 2 \\
\hline & standard count & 16 & 14 & 11 & 9 & 50 \\
\hline Nuts & Standard time $/ \mathrm{sec}$ & $1-18$ & $1-16$ & $1-12$ & $1-10$ & $4-56$ \\
\hline & standard count & 17 & 15 & 11 & 9 & 50 \\
\hline Bolts & Standard time $/ \mathrm{sec}$ & 20 & 17 & 12 & 8 & 57 \\
\hline & standard count & 1 & 1 & 1 & 1 & 4 \\
\hline
\end{tabular}

The exercise procedures were traced until the completion of each phase of junction box assembly. A sample was randomly selected and used to calculate the sigma level and the current assembly rate.

The assembly process produces (100 pieces $\times 4$ junction box $\times 4$ assemblers $\times 4$ teams $\times 3$ shifts $)=19200$.

Five types of defects were detected. The number of occurrences of each defect type is listed in Table III below:

TABLE III. TYPES OF DEFECTS AND NUMBER OF OCCURRENCES

\begin{tabular}{|c|c|}
\hline Defect type & Number of occurrences \\
\hline Missing washer & 73 \\
\hline Double washers & 42 \\
\hline Defective part & 16 \\
\hline Loose assembly & 8 \\
\hline Cracked junction box & 2 \\
\hline Total number of defects & $\mathbf{1 4 1}$ \\
\hline
\end{tabular}

\section{Define defects}

A Defect is defined as delay of the assembly process at any stage leading to the increase in the assembly time of each set of the junction box.

$$
\begin{aligned}
& \text { Defect Per Million Opportunity }(D P M O)= \\
& \frac{\text { Total No. of Defects }}{\text { Total No. of pieces } \times \text { Opportunities }} \\
& D P M O=(141 \times 1000,000) /(19200 \times 5)=1468.75
\end{aligned}
$$

Sigma level for the above value of DPMO is equal to $=4.47$

\section{J. Analyze Phase}

Analysis was performed on variables for which data can be readily collected, and then statistical analysis was used to test whether these factors (Xs) had an influence on the project's index (Y) or not. For the statistical analysis, one set of the junction box assembly was randomly sampled from each shift over two weeks. Each assembly was re-assembled to evaluate whether or not it would improve the assembly count and time. Figure 4 shows the main effects plot for each factor with regard to assembly count.

Figure 5 identified the root cause analysis as follows:

1. Manpower: students were unfamiliar with the teambased project, and they were speeding up the assembly process without paying attention to the sequence of the assembly process.

2. Method: the process sequence was designed to facilitate a smooth assembly flow, but most students were rushing to randomly assemble the junction box which resulted in over processing and inventory waste

3. Materials: the mix-up of washers, nuts and bolts in containers was found to be the main cause of delay, and the absence of size identification marks on the used items was causing time loss.

4. Machine: part of the exercise was performed using the conveyor belt. The speed of the conveyor enhanced the 
assembly process by reducing the motion and waiting time.

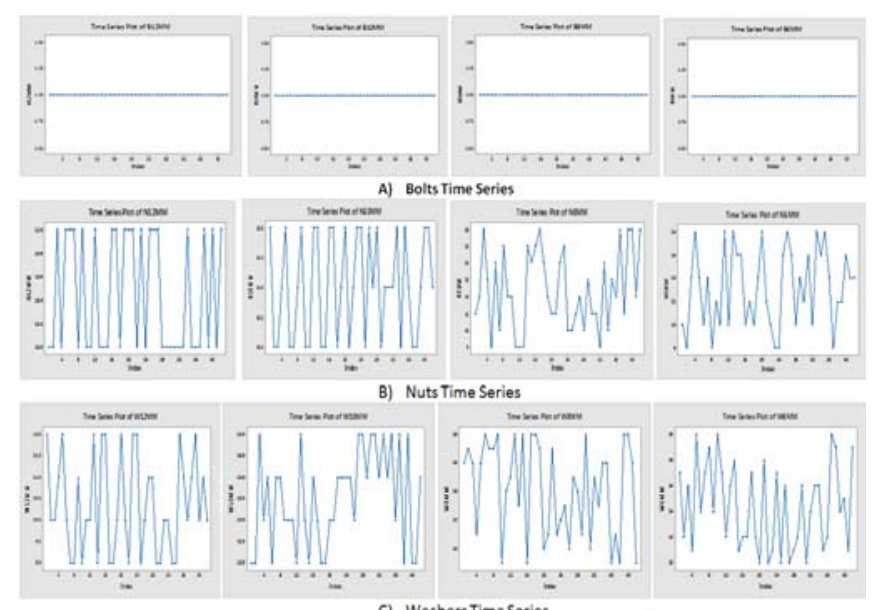

Fig. 4. Random sample re-assembled data count

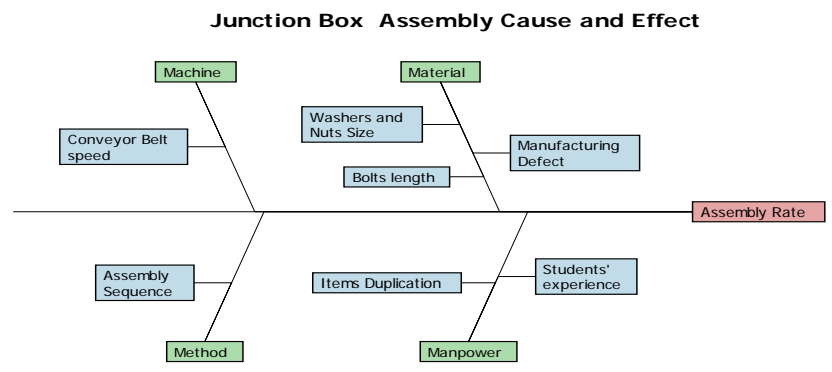

Fig. 5. Junction Box Assembly Cause and Effect

The Pareto chart in figure (6) indicates the major reasons for the delay of the assembly process.

\section{K. Improve Phase: Applying 5 S tool in Lean Six Sigma Define phase}

The purpose of the $5 \mathrm{~S}$ Model is to improve the assembly process by organizing the workplace through the following steps in Table IV. The model begins with a normal mode where the assembly process starts random. Then, an evaluation session for the count and waste identification is established according to the eight types of wastes. The collected data from the pilot test show an incremental improvement in the assembly processing. The measurement during the pilot test focused on the cycle time of each assembly and counting the repetition of the non-value added activities (waste).

\section{Control Phase}

Control phase was critical to sustain the improvements made during previous phase and to maintain the solution for the problem. Visual control was a common quality tools to keep tracking and managing the assembly processing in order to continuously improve the process.

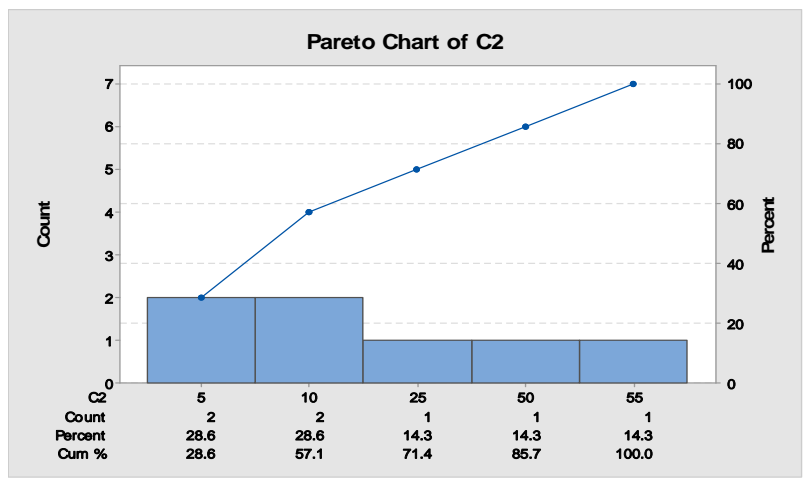

Fig. 6. Reasons for the delay of assembly process

TABLE IV. 5S LEAN MANUFACTURING TOOL

\begin{tabular}{|c|c|c|}
\hline $5 S$ & Goal & Eliminate or Correct \\
\hline Sort & $\begin{array}{l}\text { Keep only what } \\
\text { you need }\end{array}$ & $\begin{array}{l}\text { Sort out WBN in separate containers } \\
\text { according to size }\end{array}$ \\
\hline Set in order & $\begin{array}{l}\text { A place for } \\
\text { everything and } \\
\text { everything in } \\
\text { its place }\end{array}$ & $\begin{array}{l}\text { Arrange containers according to size from } \\
\text { right to left starting with } 6 \mathrm{~mm} \text { and unto } 12 \\
\mathrm{~mm}\end{array}$ \\
\hline Shine & $\begin{array}{l}\text { Cleaning, and } \\
\text { looking for } \\
\text { ways to keep } \\
\text { clean and } \\
\text { organized }\end{array}$ & $\begin{array}{l}\text { Clean the assembly area surfaces, remove } \\
\text { items not needed in the exercise activities }\end{array}$ \\
\hline Standardize & $\begin{array}{l}\text { Monitoring the } \\
\text { first three } \\
\text { categories. } \\
\text { Sticking to the } \\
\text { rules }\end{array}$ & $\begin{array}{l}\text { Start the assembly process clockwise } \\
\text { starting from } 6 \mathrm{~mm} \text { unto } 12 \mathrm{~mm} \text {, Label the } \\
\text { containers and the process sequence }\end{array}$ \\
\hline Sustain & $\begin{array}{l}\text { To maintain } \\
\text { Lean six sigma } \\
\text { process }\end{array}$ & $\begin{array}{l}\text { Number of workers without } 5 \mathrm{~S} \text { training; } \\
\text { number of daily } 5 \mathrm{~S} \text { inspections not } \\
\text { performed; number of personal items not } \\
\text { stored; number of times job aids not } \\
\text { available or up-to-date }\end{array}$ \\
\hline
\end{tabular}

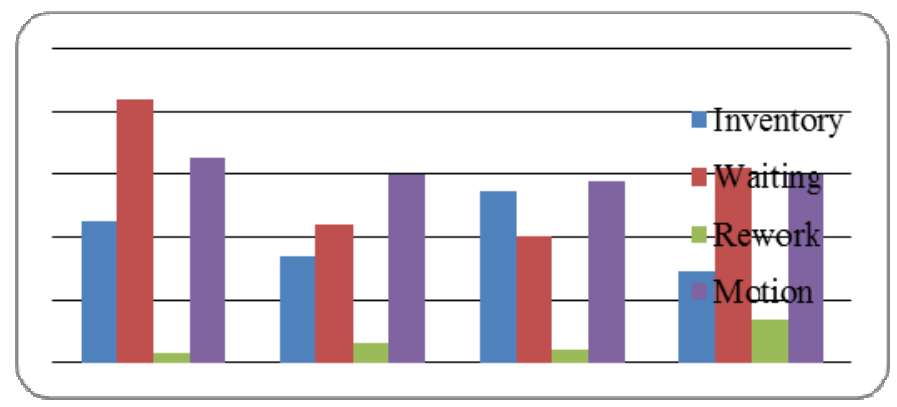

Fig. 7. Lean Six Sigma Mode: parts count

\section{DISCUSSION}

The observation of the Lean Six Sigma exercises revealed that Lean Six Sigma tools were used to identify and improve some input variables (critical Xs) in a process. In some cases one of the critical Xs may be related to technical problems. In such case, the application of Lean Six Sigma could be beneficial in solving and improving the critical X. However, it would be fair to say, that Lean is best used to address 
production (or physics) problems [9] where flow in the process is not optimal, whereas Six Sigma is useful in identifying defects. Total productivity could be improved by taking care of the critical Xs through the following activities:

X1: enhancing flexibility of resources utilization to optimize the flow of process by:

- using individual containers in each assembly area

- adding a table behind the assembly area to allow simultaneous to work on multiple tables

- using the belt conveyor

- X2: eliminate waste through improved inventory control

- reconfiguring the container-refill sequence

- reducing the inventory level to a maximum of 50 per pin

- using visual controls to display product status according to a color code

- X3: Pull system

- Initiating Kanban inventory control

- Status inventory and develop Electronic Inventory Logs to track storage

- $\mathrm{X} 4$ : Standardize work

- preparing a list of standardized activities with clear roles, responsibilities and accountabilities

- conducting the assembly process clockwise starting from $6 \mathrm{~mm}$ and unto $12 \mathrm{~mm}$.

- labelling the containers and the process sequence and using colour codes

\section{CONCLUSION}

This study demonstrated the key steps in developing innovative and creative hands-on exercises which introduce students to Lean Six Sigma and utilizes the assembly line concept for data collection. Four modules have been 'studenttested' as exercises appropriate for quality in manufacturing courses: the normal, 5-s, stationary and motion modes. These modes can be disseminated to other engineering courses. There is considerable scope for developing more modules to broaden the incorporation of Lean Six Sigma topics and the depth and extent of quality and manufacturing. Waste elimination and variation reduction prove very useful in generating sufficientlylarge (statistically significant) data for Lean Six Sigma analysis. In addition, the study has shown that Design for Manufacturing and Assembly is a methodology that works well in facilitating Lean Six Sigma through waste elimination and cycle time minimization. The washers, bolts, and nuts junction box assembly was found to be an efficient and easy to use in Lean Six Sigma model to measure the level of improvement in the manufacturing process. Overall, the study was rather enjoyable and beneficial for students and enhanced the quality of the engineering education process. It is recommended that each Lean Six Sigma hands-on be visualized through computer graphics virtual manufacturing programs before hands-on practice.

\section{ACKNOWLEDGMENT}

The current undertaken research is supported by funded by the Ministry of Education within the framework of the National Initiative on Creativity and Innovation in Saudi Universities and the Deanship of Academic Research at University of Hail by a grant for project number (E-26-IC). This is gratefully acknowledged.

\section{REFERENCES}

[1] L. Carlson, J. Sullivan, "First year engineering projects: an interdisciplinary, hands-on introduction to engineering", ASEE Annual Conference, pp. 2039-2043, 1995

[2] I. Elbadawi, D. McWilliams, T. Tetteh, "Enhancing Lean Manufacturing: Learning Experience through Hands-on Simulation Exercises", Simulation and Gaming Journal, Vol. 41, No. 4, pp. 537552,2010

[3] I. Elbadawi, "3D Design Process for Manufacturing and Assembly Table Top Tools for Incremental Continuous Improvement (Kaizen)", Technology Interface international Journal, Vol. 15, No. 1, pp. 28-34, 2014

[4] A. K. Verma, Simulation Tools and Training Programs in Lean Manufacturing, NSRP-ASE Report No.0301-11, Norfolk, VA: Old Dominion University, 2003

[5] M. L. George, Lean Six Sigma: Combining Six Sigma Quality with Lean Speed, McGraw-Hill, New York, NY, 2002

[6] J. Womack, D. Roos, D. Jones, The Machine That Changed the World: The Story of Lean Production, Harper Perennial, 1991

[7] J. Womack, D. Jones, Lean Thinking, Simon \& Schuster, New York, 1996

[8] D. Montgomery, Introduction to Statistical Quality Control, John Willey \& Sons, Inc., New York, NY, 2004

[9] G. Ballard, The Last Planner System of Production Control; Ph.D. Dissertation, The University of Birmingham, U.K., 2000 